\title{
DUKUNGAN SOSIAL ORANG TUA DAN PSYCHOLOGICAL WELL BEING PASCA PUTUS CINTA PADA DEWASA AWAL
}

\author{
Jovina Amanda Sugiarto ${ }^{1}$, Christiana Hari Soetjiningsih ${ }^{2}$ \\ jovinaamanda31@gmail.com,soetji_25yahoo.co.id ${ }^{1}$ \\ Universitas Kristen Satya Wacana ${ }^{1,2}$
}

\begin{abstract}
Abstrak
Penelitian ini bertujuan untuk mengetahui hubungan antara dukungan sosial orang dengan pasca putus cinta pada dewasa awal. Dukungan sosial adalah suatu proses hubungan yang terbentuk dari individu dengan persepsi bahwa seseorang dicintai dan dihargai, disayang untuk memberikan bantuan kepada individu yang mengalami tekanan dalam kehidupannya. Dukungan sosial yang dimaksud dalam penelitian ini adalah dukungan sosial orang tua. Subjek penelitian ini adalah laki-laki dan perempuan berusia 18-40 tahun yang mengalami putus cinta maksimal 1 tahun terakhir dan mengalami kesedihan yang mendalam pasca putus cinta. Skala dukungan sosial yang digunakan dalam penelitian ini menggunakan skala dari Weiss dan skala Psychological Well Being menggunakan dari Ryff. Analisis data menggunakan korelasi Pearson Product Moment. Hasil penelitian menunjukan bahwa dukungan sosial orang tua tinggi sebesar $68,75 \%$ dan Psychological Well Being yang tinggi juga sebesar 81,25\%. Hipotesis penelitian ini diterima dengan hasil penelitian yang menunjukkan adanya hubungan positif signifikan antara dukukungan sosial orang tua dengan psychological well being dengan $\mathrm{r}=0,611$ dan nilai signifikansi $0,000(\mathrm{p}<0,05)$. Artinya semakin tinggi dukungan sosial orang tua maka semakin tinggi juga psychological well being yang dimiliki oleh dewasa awal pasca putus cinta demikian sebaliknya.
\end{abstract}

Kata kunci : Dukungan Sosial, Kesejahteraan Psikologis, Dewasa Awal, Putus Cinta

\begin{abstract}
This study aims to determine the relationship between social support and post-breakup in early adulthood. Social support is a process of relationship that is formed from individuals with the perception that someone is loved and valued, loved to provide assistance to individuals who experience pressure in their lives. The social support referred to in this study is the social support of parents. The subjects of this study were men and women aged 18-40 years who experienced a maximum breakup last 1 year and experienced deep sadness after a breakup. The social support scale used in this study uses the scale of Weiss and the Psychological Well Being scale using that of Ryff. Data analysis uses Pearson Product Moment correlation. The results showed that parents' social support was high at $68.75 \%$ and Psychological Well Being was also high at $81.25 \%$. The hypothesis of this study was accepted by the results of the study which showed a significant positive relationship between social support of parents with psychological well being with $r=$ 0.611 and a significance value of 0.000 ( $p<0.05$ ). This means that the higher the social support of parents, the higher the psychological well being possessed by early adulthood after a breakup and vice versa.
\end{abstract}

Keywords: Social Support, Psychological Well Being, Early Adulthood, Breakup

\section{PENDAHULUAN}

Manusia merupakan makhluk sosial sehingga tidak dapat hidup sendiri.

Menurut Miller dan Perlman (2009), hubungan dengan orang lain adalah aspek utama dari kehidupan seorang individu yang dapat menimbulkan kebahagiaan yang besar ketika hubungan tersebut berjalan dengak baik tetapi juga sebaliknya, dapat menimbulkan kesedihan yang luar biasa ketika hubungan memburuk. Ada beberapa bentuk hubungan sosial salah satunya adalah hubungan intim lawan jenis atau 
hubungan romantis. (Myers 2012) Hubungan yang terjalin baik diharapkan akan mencapai ke jenjang pernikahan lalu membangun rumah tangga dimana ini merupakan tugas perkembangan dewasa awal. Dewasa awal berada dimasa mereka mulai memilih pasangan hidup dan belajar untuk berkeluarga dan membina rumah tangga (Santrock, 2002). Menurut teori perkembangan, masa menikah adalah saat usia dewasa awal atau dewasa muda yaitu 20-40 tahun atau usia 18-40 tahun (Hurlock, 1980)

Namun dalam hubungan romantis tidak selalu berakhir dengan pernikahan. Ada yang hubungan romantis berakhir sebelum pernikahan atau putus cinta. Menurut Yuwanto (2011), putus cinta merupakan kejadian berakhirnya suatu hubungan cinta yang telah dijalin dengan pasangannya. Putus cinta dapat memberikan dampak yang negatif. Menurut Lavine dalam Lolong (2003), individu yang mengalami putus cinta merasakan takut, sedih, kecewa, menderita. Hasil penelitian yang dilakukan oleh Yulianingsih (2012) terhadap siswa di SMK Negeri 8 Surakarta dan SMK Batik 1 Surakarta, diketahui bahwa sebanyak 57,45\% siswa mengalami kesedihan setelah mengalami putus cinta, 21,04\% merasa galau, 13\% biasa-biasa saja, 7,98\% justru merasa bahagia, dan sebanyak $1,06 \%$ merasa marah. Kemudian sebanyak $68,62 \%$ siswa merasakan kesedihan selama kurang dari satu bulan, $14,89 \%$ selama tiga sampai enam bulan, $4,25 \%$ selama enam bulan sampai satu tahun, dan sebanyak 4,79\% mengalami kesedihan selama lebih dari satu tahun.

Menurut Rumondor (2013) didasarkan pada pengamatannya dalam praktik sebagai psikolog klinis, sedikitnya 5 orang dalam jangka waktu 8 bulan, wanita dewasa muda datang ke klinik untuk mencari bantuan mengatasi dampak dari pemutusan hubungan romantis yang baru saja dialami. Dampak yang dirasakan antara lain perasaan sedih, kehampaan, perasaan gagal dan kehilangan kepercayaan diri, sulit berkonsentrasi, hingga timbul pikiran untuk bunuh diri. Dari ini data dikatakan bahwa pemutusan hubungan romantis memiliki dampak yang negatif bagi dewasa muda.

Terlebih hubungan romantis yang dijalin di usia dewasa awal diharapkan bisa menjadi hubungan yang serius hingga ke jenjang pernikahan karena salah satu tugas perkembangan dewasa awal adalah memasuki kehidupan berkeluarga (Santrock,2002). Dampak dari putus cinta seperti yang terurai diatas dapat menggambarkan bahwa jika seseorang mengalami dampak negatif dari putus cinta ada perasaan gagal pada dalam dirinya yang membuat kehilangan 
kepercayaan diri bahkan merasa kehilangan tujuan hidup sehingga terlintas di pikiran untuk mengakhiri hidupnya atau bunuh diri. Dalam hal ini dapat diartikan bahwa Psychological Well Being (PWB) pada individu tidak baik.

PWB adalah realisasi dan pencapaian penuh dari potensi individu dimana individu dapat menerima segala kekurangan dan kelebihan dirinya, mandiri, mampu membina hubungan yang positif dengan orang lain, dapat menguasai lingkungannya dalam arti dapat memodifikasi lingkungan agar sesuai dengan keinginannya, memiliki tujuan dalam hidup, serta terus mengembangkan pribadinya (Ryff, 1989).

Dikarenakan individu merasakan keterpurukan dan tidak merasa bahagia maka secara tidak langsung akan membuat PWB yang rendah, karena dari pengalaman hidup yang buruk yang diterima oleh individu. Alih-alih memotivasi diri untuk bangkit kembali dan menemukan tujuan hidup, ada orangorang yang memilih mengakhiri hidupnya atau bunuh diri dikarenakan putus cinta. Seperti yang dilansir oleh Tribun Timur yang ditulis oleh Surya Malang (Rabu, 27/7/2016), seorang mahasiswa bernama Efr (20tahun) ditemukan tewas di rumahnya di kawasan Petukangan Selatan, Pesanggrahan, Jakarta Selatan, Rabu (27/7/2016), ia diduga gantung diri akibat putus cinta. Tidak hanya pria, kasus lainnya juga terjadi pada wanita, seperti yang diberitakan pada inews.id oleh Irfan Ma'ruf, Kamis (15/08/2019), seorang wanita berinisial PD berusia 25 tahun memilih untuk mengakhiri hidupnya dengan gantung diri diperkirakan dikarenakan putus cinta.

Individu yang terpuruk saat putus cinta seakan kehilangan tujuan hidup, tidak bisa berpikir jernih, tidak dapat menerima keadaan, penyesalan terhadap diri sendiri, dan terus membiarkan dirinya berada dalam kesedihan bukan mencari hal positif untuk bangkit kembali. Hasil penelitian Riani (2017) menunjukkan, bahwa dukungan sosial keluarga memiliki hubungan yang signifikan positif dengan kestabilan emosi remaja pasca putus cinta. Dalam artian dukungan sosial keluarga yang tinggi akan memberikan kestabilan emosi. Menurut Rodin dan Salovey (1989, dalam Smet, 1994), dukungan sosial terpenting berasal dari keluarga. Di sini dapat dikatakan orang tua merupakan bagian dalam keluarga yang memiliki kedekatan paling dalam dengan sang anak. Santrock (2002) menjelaskan bahwa orang tua berperan sebagai tokoh penting dengan siapa anak menjalin hubungan dan merupakan suatu sistem dukungan ketika anak menjajaki suatu dunia sosial yang lebih luas dan lebih kompleks. Bila mendapat dukungan sosial yang cukup 
dari orang tua maka bisa mempengaruhi PWB orang tersebut. Karena dalam menghadapi masa sulit peran orang lain diperlukan untuk membantu meringankan beban dengan kata lain bisa mendapat dukungan secara emosional. Seperti penelitian yang dilakukan oleh Dinova (2016) bahwa semakin tinggi dukungan sosial maka semakin tinggi juga PWB.Saat adanya dukungan sosial yang cukup, individu merasa tidak lagi sendiri dalam menghadapi permasalahannya dan dapat melanjutkan kehidupan dengan baik, bisa menentukan kembali tujuan hidupnya, mulai membangun hubungan positif dengan orang lain lagi, melakukan hal-hal positif bagi dirinya, dan bertanggung jawab dengan kehidupannya.

Psychological well being adalah realisasi dan pencapaian penuh dari potensi individu dimana individu dapat menerima segala kekurangan dan kelebihan dirinya, mandiri, mampu membina hubungan yang positif dengan orang lain, dapat menguasai lingkungannya dalam arti dapat memodifikasi lingkungan agar sesuai dengan keinginannya, memiliki tujuan dalam hidup, serta terus mengembangkan pribadinya (Ryff, 1989).

\section{Aspek-aspek Psychological Well Being}

Ryff (1989) menjelaskan ada enam aspek yang dapat menggambarkan PWB yang dimiliki oleh individu. Enam aspek tersebut yaitu :

1. Penerimaan diri (self acceptance)

Penerimaan diri dianggap sebagai fitur utama dari kesehatan mental dan merupakan karakteristik dari aktualisasi diri. Hal ini ditunjukkan dengan sikap dan evaluasi positif terhadap diri sendiri dimasa sekarang maupun dimasa lalu. Sikap yang positif terhadap diri sendiri merupakan karakteristik yang penting dalam fungsi psikologis yang positif.

2. Hubungan positif dengan orang lain (positive relations with others)

Hubungan yang positif dengan orang lain ditunjukkan dengan adanya kehangatan dan hubungan yang berlandaskan rasa saling percaya. Individu memiliki empati dan kasih sayang pada umat manusia, serta mampu menjadi individu yang memiliki rasa cinta yang kuat, hubungan persahabatan yang mendalam dan mampu mengidentifikasikan dirinya dengan orang lain. Teori perkembangan masa dewasa menurut Erikson (1968, dalam Ryff 1989) menekankan pada tercapainya hubungan yang dekat dengan orang lain (intimacy) dan 
bimbingan serta arahan bagi orang lain (generativity).

3. Otonomi (autonomy)

Individu memiliki locus internal dalam melakukan evaluasi, sehingga ia tidak mencari persetujuan orang lain tapi mengevaluasi dirinya dengan standar personal yang dimiliki sendiri. Individu juga mampu bertahan dari tekanan sosial untuk bertindak, berpikir dengan caracara tertentu, dan meregulasi tingkah laku dari dalam diri.

4. Penguasaan lingkungan (environmental mastery)

Individu mampu memilih atau menciptakan lingkungan yang sesuai dengan kondisi psikisnya, mampu memanipulasi dan mengontrol lingkungan yang kompleks, serta dapat bergerak maju dan melakukan perubahan secara kreatif melalui aktivitas mental dan fisik. Individu juga memiliki kemampuan untuk mengambil keuntungan dalam kesempatan-kesempatan yang ditawarkan oleh lingkungan.

5. Tujuan hidup (purpose in life)

Individu memiliki keyakinan akan tujuan dan arti kehidupan. Individu juga memiliki pemahaman yang jelas dan menyeluruh mengenai tujuan hidup, sense of directedness dan intentionality. Selanjutnya menurut teori perkembangan, terdapat perubahan tujuan dalam hidup agar menjadi individu yang lebih produktif, kreatif dalam mencapai integrasi emosional pada tahapan perkembangan selanjutnya.

6. Pengembangan pribadi (personal growth)

Individu menyadari potensi yang dimiliki dan mampu untuk terus tumbuh dan berkembang, Individu juga terbuka pada pengalaman baru dan tidak menetap hanya pada posisi tertentu setelah sebuah permasalahan berhasil dipecahkan. Faktor-faktor yang dapat mempengaruhi kesejahteraan psikologis (PWB) seseorang menurut Ryff yaitu :

- $\quad$ Faktor Demografis

Faktor demografis yang mempengaruhi kesejahteraan psikologis (PWB) yaitu usia, jenis kelamin, status sosial ekonomi, dan budaya.

Dukungan Sosial

Dukungan sosial sendiri diartikan sebagai rasa nyaman, perhatian, penghargaan, atau pertolongan yang dipersepsikan oleh seorang individu yang didapat berbagai 
sumber, diantaranya pasangan, keluarga, teman, rekan kerja, dokter, maupun organisasi sosial.

- Evaluasi terhadap Pengalaman Hidup

Pengalaman hidup mencakup berbagai bidang kehidupan dalam berbagai periode kehidupan. Evaluasi individu terhadap pengalaman hidupnya memiliki pengaruh yang penting terhadap kesejahteraan psikologis.

- $\quad$ Locus Of Control (LOC)

Locus Of Control didefinisikan sebagai suatu ukuran harapan umum seseorang mengenai pengendalian (kontrol) terhadap penguatan (reinforcement) yang mengikuti perilaku tertentu, dapat memberikan peramalan terhadap kesejahteraan psikologis (PWB).

Weiss (dalam Cutrona, 1986), menjelaskan dukungan sosial adalah suatu proses hubungan yang terbentuk dari individu dengan persepsi bahwa seseorang dicintai dan dihargai, disayang untuk memberikan bantuan kepada individu yang mengalami tekanan dalam kehidupannya. Dalam penelitian ini, yang dimaksud adalah dukungan sosial orang tua.

Weiss ( dalam Cutrona, 1986) mengembangkan Social Provisions Scale
(SPS) melalui enam aspek untuk mengukur dukungan sosial, yaitu:

a. Attachment (kasih sayang)

Yaitu perasaan akan kedekatan emosional dan rasa aman.

b. Social Integration (integrasi sosial)

Yaitu perasaan menjadi bagian dari suatu kelompok dan tempat saling berbagi minat dan aktivitas, perasaan saling memiliki.

c. Reassurance of worth (penghargaan/pengakuan)

Yaitu adanya pengakuan dari orang lain mengenai kemampuan dan kompetensinya d. Reliable alliance (ikatan/hubungan yang dapat diandalkan) Yaitu kepastian adanya seseorang yang dapat diandalkan dalam situasi apapun.

e. Guidance (bimbingan)

Yaitu adanya nasehat atau bimbingan dalam menghadapi masalah yang dialami.

f. Oppurtunity for marturance (kesempatan merasa dibutuhkan)

Yaitu perasaan akan dibutuhkan oleh orang lain

Hipotesis pada penelitian ini adalah ada hubungan positif antara dukungan sosial orang tua dengan PWB pasca putus cinta pada dewasa awal. Makin tinggi dukungan sosial orang tua maka makin tinggi PWB dan makin rendah dukungan sosial orang tua maka makin rendah PWB pasca putus cinta pada dewasa awal. 


\section{METODE PENELITIAN}

Pada penelitian ini digunakan pendekatan kuantitatif dengan metode penelitian korelasional. Partisipan penelitian ini adalah individu dewasa awal yang mengalami putus cinta. Partisipan dalam penelitian ini berjumlah 32 orang dengan teknik pengambilan sampel Purposive Sampling. Purposive Sampling adalah pengambilan sampel dilakukan dengan berdasarkan pada karakteristikkarakteristik tertentu. Adapun karakteristiknya yaitu : 1) pria atau wanita ; 2) usia 18 sampai 40 tahun ; 3) mengalami putus cinta maksimal 1 tahun terakhir. Teknik pengumpulan data yang digunakan berupa kuesioner yang berisi skala masing-masing variabel. Teknik analisis data penelitian ini menggunakan teknik korelasi Pearson Product Moment dengan menggunakan bantuan program SPSS 16.0 for windows.

\section{HASIL PENELITIAN}

Skala dukungan sosial orang tua terdiri dari 24 aitem, dengan jenjang skor 1 sampai 4; sangat tidak setuju, tidak setuju, setuju, dan sangat setuju.

\section{Tabel 1}

Kategorisasi Pengukuran Skala Dukungan Sosial Orang Tua

\begin{tabular}{llll}
\hline Interval & Kategori & Frekuensi & $\%$ \\
\hline $\begin{array}{l}78<\mathrm{X} \\
\leq 96\end{array}$ & $\begin{array}{l}\text { Sangat } \\
\text { Tinggi }\end{array}$ & 7 & 21.875 \\
\hline $\begin{array}{l}60 \mathrm{X} \\
\leq 78\end{array}$ & Tinggi & 22 & 68.75 \\
\hline $42<\mathrm{X}$ & Rendah & 2 & 6.25 \\
\hline
\end{tabular}

\begin{tabular}{llll}
\hline$\leq 60$ & & & \\
\hline $24<X$ & Sangat & 1 & 3.125 \\
$\leq 42$ & Rendah & 1 & 100 \\
\hline JUMLAH & 32 & 100 \\
\hline \multicolumn{3}{c}{ Min = 24 } & Max = 96 Mean 70.97
\end{tabular}

Dari tabel diatas dilihat bahwa responden memiliki dukungan sosial orang tua orang tua dengan kategori tinggi sebesar $68.75 \%$.

\section{Psychological Well Being}

Skala PWB memiliki 33 aitem, dengan jenjang skor antara 1 sampai 4 ; sangat tidak setuju, tidak setuju, setuju dan sangat setuju.

Tabel 2

Kategorisasi Pengukuran Skala Psychological Well Being

\begin{tabular}{|c|c|c|c|}
\hline Interval & Kategori & Frekuensi & $\%$ \\
\hline $\begin{array}{l}107.25 \\
<X \leq 132\end{array}$ & $\begin{array}{l}\text { Sangat } \\
\text { Tinggi }\end{array}$ & 0 & 0 \\
\hline $\begin{array}{l}82.5<X \\
\leq 107.25\end{array}$ & Tinggi & 26 & 81.25 \\
\hline $\begin{array}{l}57.75<X \\
\leq 82.5\end{array}$ & Rendah & 5 & 15.625 \\
\hline $\begin{array}{l}33<\mathrm{X} \\
\leq 57.75\end{array}$ & $\begin{array}{l}\text { Sangat } \\
\text { Rendah }\end{array}$ & 1 & 3.125 \\
\hline JUMLAH & & 32 & 100 \\
\hline \multicolumn{4}{|c|}{ Min $=33$ Max $=132$ Mean 92.125 SD } \\
\hline
\end{tabular}

Dari tabel diatas dapat dilihat bahwa responden memiliki PWB tinggi dengan presentase $81.25 \%$.

\section{Uji Normalitas}

Uji normalitas bertujuan untuk mengetahui normal atau tidaknya distribusi data masing-masing variabel. 
Tabel 3 Uji Normalitas

One-Sample Kolmogorov-Smirnov Test

\begin{tabular}{|c|c|c|c|}
\hline & & $\mathrm{X}$ & $\mathrm{Y}$ \\
\hline $\mathrm{N}$ & & 32 & 32 \\
\hline \multirow[t]{3}{*}{ Normal Parameters } & Mean & 70.97 & 92.12 \\
\hline & Std. & 10.43 & 12.37 \\
\hline & Deviation & 7 & 5 \\
\hline \multicolumn{4}{|l|}{ Most Extreme } \\
\hline \multirow[t]{3}{*}{ Differences } & Absolute & .182 & .185 \\
\hline & Positive & .131 & .159 \\
\hline & Negative & -.182 & -.185 \\
\hline \multicolumn{4}{|l|}{ Kolmogorov- } \\
\hline Smirnov Z & & 1.028 & 1.049 \\
\hline $\begin{array}{l}\text { Asymp. Sig. (2- } \\
\text { tailed) }\end{array}$ & & .241 & .221 \\
\hline
\end{tabular}

Dari hasil uji normalitas bahwa sampel berdistribusi normal, pada variabel dukungan sosial orang tua diperoleh KS-Z $=1.028$, n.signifikansi $0.241(\mathrm{p}>0,05)$, pada variabel PWB ditemukan KS-Z = 1.049, n.signifikansi 0,221 ( $\mathrm{p}>0,05)$.

\section{Uji Linearitas}

Hasil dari uji linearitas menunjukkan bahwa adanya hubungan yang linear antara dukungan sosial orang tua dengan PWB dengan nilai $\mathrm{F}$ beda $=2.469 \mathrm{P}=$ 0,052 ( $>0,05)$. Dari hasil uji asumsi menunjukkan bahwa data yang diperoleh berdistribusi normal dan variabel-variabel penelitian linear.

\section{Uji Korelasi}

Dari hasil uji asumsi, data yang diperoleh dinyatakan berdistribusi normal dan variabel-variabel penelitian linear, maka dalam penelitian ini digunakan uji korelasi statistik parametik. Uji korelasi yang digunakan dalam penelitian ini adalah korelasi product moment dari Pearson.

\section{Tabel 4 Uji Korelasi Dukungan Sosial Orang}

Tua dengan Psychological Well Being

\section{Correlation}

\begin{tabular}{llrr} 
& & X & \multicolumn{1}{c}{ Y } \\
\hline Prososial & Pearson Correlation & 1 & $.611^{* *}$ \\
\hline & Sig. (1-tailed) & & .000 \\
\cline { 2 - 4 } & $\mathrm{N}$ & 32 & 32 \\
\hline Empati & Pearson Correlation & $.611^{* *}$ & 1 \\
\hline & Sig. (1-tailed) & .000 & \\
\cline { 2 - 4 } & $\mathrm{N}$ & 32 & 32 \\
\hline
\end{tabular}

Dari hasil uji korelasi diatas menunjukkan adanya hubungan positif yang signifikan antara dukungan sosial orang tua dengan PWB dengan $r=0,611$ dan nilai signifikansi $0,000 \quad(\mathrm{p}<0,05)$. Sehingga, hipotesis dalam penelitian ini diterima. Hasil ini menunjukkan bahwa dukungan sosial orang tua yang tinggi maka tinggi juga PWB pada dewasa muda pasca putus cinta dan sebaliknya.

\section{PEMBAHASAN}

Berdasarkan hasil uji korelasi menunjukan adanya korelasi positif yang signifikan antara dukungan sosial orang tua dengan PWB pada dewasa awal pasca putus cinta dengan $r=0,611$ dan nilai signifikansi 0,000 $(\mathrm{p}<0,05)$. Hasil ini menunjukkan bahwa dukungan sosial orang tua yang tinggi menciptakan PWB yang tinggi pada dewasa awal pasca putus cinta begitu juga sebaliknya. Berdasarkan hasil tersebut dimana ada korelasi positif signifikan berarti hipotesis penelitian ini diterima. Dilihat dari hasil penelitian 
dengan dukungan sosial orang tua yang masuk dalam kategori tinggi sebesar $68.75 \%$ dan untuk PWB ada pada kategori tinggi sebesar $81.25 \%$.

Penelitian ini selaras dengan penelitian dari Dinova (2016) bahwa semakin tinggi dukungan sosial maka semakin tinggi juga PWB. Penelitian lain dari Adha (2018) menyatakan bahwa adanya hubungan positif antara dukungan keluarga dengan kesejahteraan psikologis ibu bekerja penuh waktu. Penelitian lain berasal dari Desiningrum (2010) yang menemukan bahwa dukungan keluarga memiliki korelasi positif dengan kesejahteraan psikologis lansia. Penelitian lain dari Harum (2013) menunjukkan bahwa ada hubungan positif yang sangat signifikan antara dukungan sosial keluarga dengan kesejahteraan siswa.

Santrock (2002) menjelaskan bahwa orang tua berperan sebagai tokoh penting dengan siapa anak menjalin hubungan dan merupakan suatu sistem dukungan ketika anak menjajaki suatu dunia sosial yang lebih luas dan lebih kompleks. Maka peran orang tua di sini penting untuk memberikan dukungan kepada anak di masa sulit seperti saat sedang putus cinta, karena beberapa anak merasakan kesedihan yang mendalam yang membuat PWB-nya menjadi terganggu. Dengan adanya dukungan sosial yang tinggi dari orang tua, maka individu tersebut tidak merasa sendiri saat menghadapi masalah, individu bisa mendapatkan bimbingan dari orang tua sehingga mereka tau apa yang harus dilakukan, mereka akan merasakan kasih sayang dan memiliki hubungan yang dapat diandalkan, perasaan saling memiliki dan saling membutuhkan, dengan ini individu dapat menemukan kembali tujuan hidupnya karena adanya bimbingan dan melajutkan hidupnya tanpa beban masa lalu. Individu juga lebih dapat menerima diri dengan menunjukan evaluasi positif terhadap dirinya sendiri juga bisa memiliki hubungan positif dengan orang lain karena adanya satu ikatan dimana saling membutuhkan, memiliki dan rasa aman, baik dengan sesama mau pun lawan jenis.

Menurut Rodin dan Salovey (1989, dalam Smet, 1994), dukungan sosial terpenting berasal dari keluarga. Salah satunya dukungan sosial orang tua, dimana ketika anak merasakan dukungan dari orang tua mereka, maka mereka akan mempunyai PWB yang tinggi sehingga mereka lebih mampu untuk menghadapi permasalahan yang sedang dihadapi.

\section{PENUTUP}

\section{Kesimpulan}

Berdasarkan hasil penelitian diatas dapat disimpulkan bahwa : 
1. Adanya hubungan positif signifikan antara dukungan sosial orang tua dengan PWB. Makin tinggi dukungan sosial orang tua maka makin tinggi PWB dan makin rendah dukungan sosial orang tua maka makin rendah PWB pasca putus cinta pada dewasa muda.

2. Dukungan sosial orang tua memiliki sumbangan efektif terhadap PWB sebesar $37,3 \%$ dan $62,7 \%$ lainnya berasal dari variabel lain.

3. Dukungan sosial orang tua berada pada kategori tinggi dengan presentase 68,75\% dan PWB pada kategori tinggi dengan presentase $81,25 \%$

\section{Saran}

Berdasarkan dari hasil penelitian yang telah dilakukan, terdapat beberapa saran yang dapat diberikan oleh peneliti:

1. Bagi subjek

Bagi subjek, diharapkan bisa lebih menerima dan menghargai setiap dukungan sosial yang diberikan oleh orang tua karena di sini dukungan sosial orang tua berperan penting bagi PWB subjek.

2. Bagi orang tua

Bagi orang tua, diharapkan bisa lebih memberikan dukungan sosial orang tua bagi anak-anaknya yang mengalami kesedihan pasca putus cinta karena dukungan sosial orang tua dari orang tua memiliki peran penting bagi anaknya.

3. Bagi peneliti selanjutnya

Bagi peneliti, penelitian ini dapat dijadikan referensi untuk penelitian selanjutnya, bisa lebih diperjelas perbedaan subjek penelitian antara laki-laki dan perempuan, juga dapat ditambahkan variabel lainnya.

\section{DAFTAR PUSTAKA}

Adha, H.D. (2018). Hubungan Antara Dukungan Keluarga Dan Kesejahteraan Psikologis Pada Ibu Pekerja Penuh Waktu. Skripsi, Yogyakarta: Universitas Islam Indonesia Yogyakarta.

Cutrona, C. E. \& Russell, D. W. (1987). The provisions of social relationships and adaptation to stress. Advances in Personal Relationships, Vol. 1, 37-67

Desiningrum, D.R. (2010). Family's social support and psychological well-being of the elderly in tembalang. Anima, Indonesian Psychological Journal, 26 (1), 61 -68 .

Dinova, A.K. (2016).Hubungan Dukungan Sosial Dengan Psychological Well-Being Pada Remaja Panti Asuhan. Malang : Universitas Muhammadiah Malang.

Erikson, E. H. (1968). Identity, youth, and Crisis.International University Press. New York.

Fadilah. (2016). Pengaruh Rasa Syukur dan Kepribadian Terhadap 
Psychological Well-Being pada Orang Tua yang Memiliki Anak Berkebutuhan Khusus. Jakarta : Universitas Islam Negeri Syarif Hidayatullah.

Harum, R.K.S. (2013). Hubungan Antara Dukungan Sosial Keluarga Dengan Kesejahteraan Siswa Di Smp Negeri 16 Surakarta. Surakarta : Universitas Muhammadiyah Surakarta.

Hurlock, Elizabeth B. (1980). Psikologi Perkembangan: Suatu Pendekatan Sepanjang Rentang Kehidupan (Edisi Kelima). Jakarta: Erlangga.

Lolong, Oktafianingsih. F. (2003). Hubungan antara Coping Strategy dengan Adaptational Outcomes pada Mahasiswa yang Mengalami Stress Pasca Putus Cinta. Prosiding Psikologi, ISSN : 2460-6448.

Malang, Suryo. (2016). Mahasiswa gantung diri akibat putus cinta. Tribun-timur-com. Diakses 27/07/16.

Miller, R. S., \& Perlman, D. (2009). Intimate relationship 5th edition. Mc-Graw Hill.

Myers, D. G. (2012). Psikologi sosial. Buku 2 : Edisi 10. Jakarta: Salemba Humanika.
Riani, A. H. (2017). Hubungan Antara Dukungan Sosial Keluarga Dengan Kestabilan Emosi Pada Remaja yang Sedang Putus Cinta. Semarang : Universitas Katolik Soegijapranata.

Rumondor, P. C. B. (2013). Gambaran Prsoes Putus Cinta Pada Wanita Dewasa Di Jakarta. Jakarta : Binus University.

Ryff, C. D. (1989). Happiness is everything, or is it? Explorations on the meaning of psychological wellbeing.Journal of Personality and Social Psychology, 57(6), 10691081.

Santrock, John. W. (2012). Life-Span Development Buku 13th Edition. University of texas, Dallas : Mc Grow-Hill

Smet, Bart. (1994). Psikologi Kesehatan. Jakarta : Grasindo.

Yulianti, Y. (2012). Strategi Coping Pada Remaja Pasca Putus Cinta. Surakarta : Universitas Muhammadiyah Surakarta.

Yuwanto, L. (2011). Reaksi Umum Putus Cinta. Reatrieved from http://www.ubaya.ac.id/ ubaya/articles_detail/24/ReaksiUmum-Putus-Cinta. html. Diakses pada 8 September 2016 pukul 06:05 WIB. 